\title{
Improved Outcome of Infants Born at less than 24 Weeks of Gestation in Japan
}

\section{Hiroshi Nishida*}

Department of Health Information and Statistics, Tokyo Women's Medical University, Tokyo, Japan

\begin{abstract}
Japan neonatologist association had surveyed of survival rates of infants less than 24 weeks of gestation born during 1995 to 2001 and during 2002 to 2004 . There was no survival on $20^{\text {th }}$ and $21^{\text {st }}$ weeks of gestations, while survival rates of 22 and 23 weeks had increased from $18 \%$ to $31 \%$ and $43 \%$ to $56 \%$ respectively between two studies time periods. Their follow up data at 5 years old reviled as follows; rates of cerebral palsy (CP) with/without mental retardation (MR), MR only, blindness and infants of any aforementioned neurological sequels were $17 \%, 26 \%, 8 \%$ and $44 \%$, respectively. Main causes of death of these infants are mostly due to extreme prematurity including fragile skin and immature immunity. To improve the outcome of infants at 22 to 23 weeks of gestation, meticulous and gentle care is essential while knowing the viability limit based on their up-to-date statistics.
\end{abstract}

Keywords: ELBW infants; Marginally viable infants; Medical ethics

\section{Introduction}

Because of the advancement of obstetrical, perinatal and neonatal managements, outcome of extremely low birth weight (ELBW) infants have been markedly improved and currently survival rate of ELBW infants born at 24 weeks or more gestations became $80 \%$ or more in Japan [1-8]. Therefore, if ELBW infant's gestational age is 24 weeks or more, active intervention for those infants is widely accepted in Japan, unless the infant has lethal problems at birth. Since the viability limit of fetus is defined to be 22 completed weeks of gestation in Japan at 1991 based on national statistics of infants less than 24 weeks of gestation, we present Japanese experience on infants at 22 and 23 weeks of gestations, to whom active medical intervention are still on debate [2].

\section{Method and Results}

Two nationwide surveys and one institutional data on ELBW infants focused on infants less than 24 weeks of gestation are presented.

\section{Chronological changes of survival rates of ELBW infants in neonatal committee of Japan}

Pediatric Association has been conducting nationwide follow up study on ELBW infants every 5 years since 1980 [6-8]. There was no survival less than 500 grams at birth before 1980 but close to half (44\%) of such ELBW infants and 85\% of ELBW infants above 500 grams at birth have survived on the survey of 2000 (Table 1). When the survival rates of ELBW infants (surveyed in 2005) are categorized by gestational age, there are quite different survival rates between each gestational age group (Table 2). There was no survival on 21 weeks of gestations but survival rate of infants after 22 weeks were increased along with the advancement of gestation as follows: $34 \%$ at 22 weeks, $54 \%$ at 23 weeks, $77 \%$ at 24 weeks, $85 \%$ at 25 weeks, $90 \%$ at 26 weeks, $92 \%$ at 27 weeks and $92 \%$ at 28 weeks of gestation. Based on these data, it is apparent that ELBW infants at 21 weeks or less are not viable and infants above 24 weeks of gestation have chance to survive close to $80 \%$ or more, which elucidates the importance of infants at 22-23 weeks of gestation. These infants are regarded to be marginal viable, which will require medical and ethical consideration before initiating active interventions.

\section{Survival rates of ELBW infants less than 24 weeks of gestation according to Japan neonatologist association}

It has conducted surveys at two separate time periods on survival rates of ELBW infants less than 24 weeks of gestation born during 1995 to 2001 and during 2002 to 2004 respectively [1-8]. Reply rates were $106 / 198$ (55\%) and 114/205 (56\%) and numbers of enrolled infants were 842 and 580 respectively. There was no survival on 20 and 21 weeks of gestation on both surveys. At 22 and 23 weeks of gestation, survival rates had increased from $18 \%$ to $31 \%$ and $43 \%$ to $56 \%$, respectively (Table 3$)$, which was a statistically significant $(\mathrm{P}<0.01)$ improvement in survival rates in two time periods on both 22 weeks and 23 weeks of gestation categories (Figure 1). These data encourage us to pursue further improvement of medical care on these marginally viable infants. Follow up data of neurological sequels of 386 survivors out of 842 ELBW infants less than 24 weeks of gestation born in 1995-2001 were analyzed by subdividing in birth weight category (Table 4 ). Incidences of neurological sequels at 5 years old are as follows: CP (with/without MR), MR only, blindness and infants with any aforementioned sequels were $17 \%, 26 \&, 8 \%$ and $44 \%$ respectively. Though nearly half of such survivors are categorized to be neurologically abnormal, MR defined by IQ less than 70 could be over-diagnosed at 5 years old, since extremely preterm infants are still on the process of maturing even at 5 years

\begin{tabular}{|l|l|l|}
\hline B W(g) Year & $<500$ & $500-1000$ \\
\hline 1980 & $0 / 0$ & $493 / 1102(45 \%)$ \\
\hline 1985 & $5 / 52(10 \%)$ & $1085 / 1846(59 \%)$ \\
\hline 1990 & $9 / 50(18 \%)$ & $1462 / 2000(73 \%)$ \\
\hline 1995 & $39 / 132(30 \%)$ & $1789 / 2287(78 \%)$ \\
\hline 2000 & $57 / 153(37 \%)$ & $2238 / 2638(85 \%)$ \\
\hline 005 & $94 / 211(44 \%)$ & $2369 / 2854(83 \%)$ \\
\hline
\end{tabular}

[no. of survival/no. of admission (survival rate, \%)]

Table 1: Chronological Changes of Survival Rate of ELBW infants (Neonata Committee, Japan Pediatric Association).

*Corresponding author: Hiroshi Nishida, Department of Health Information and Statistics, Tokyo Women's Medical University, Tokyo, Japan, E-mail: hnishida-ind@umin.ac.jp

Received February 16, 2013; Accepted February 26, 2013; Published March 01,2013

Citation: Nishida H (2013) Improved Outcome of Infants Born at less than 24 Weeks of Gestation in Japan. J Health Med Informat S11: 001. doi:10.4172/2157. 7420.S11-001

Copyright: (c) 2013 Nishida H. This is an open-access article distributed under the terms of the Creative Commons Attribution License, which permits unrestricted use, distribution, and reproduction in any medium, provided the original author and source are credited. 
Citation: Nishida H (2013) Improved Outcome of Infants Born at less than 24 Weeks of Gestation in Japan. J Health Med Informat S11: 001. doi:10.4172/2157-7420.S11-001

Page 2 of 3

\begin{tabular}{|c|c|c|c|}
\hline & $\mathbf{n}(\mathbf{\%})$ & $\mathbf{n ~ ( \% )}$ & $\mathbf{n}(\mathbf{\%})$ \\
\hline Gestational weeks & Born alive & $\begin{array}{c}\text { Died before of postnatal } \\
\text { life 28 d }\end{array}$ & $\begin{array}{c}\text { Died during NICU } \\
\text { stay }\end{array}$ \\
\hline 22 & 97 & $57(58.8)$ & $64(66.0)$ \\
\hline 23 & 282 & $112(39.7)$ & $129(45.8)$ \\
\hline 24 & 423 & $77(18.2)$ & $99(23.4)$ \\
\hline 25 & 501 & $56(11.2)$ & $73(23.4)$ \\
\hline 26 & 542 & $35(6.5)$ & $56(10.3)$ \\
\hline 27 & 408 & $22(5.4)$ & $32(7.8)$ \\
\hline =>28 & 809 & $37(3.9)$ & $67(8.3)$ \\
\hline Unknown & 3 & $2(66.7)$ & $2(66.7)$ \\
\hline Total & 3065 & $398(13.0)$ & $522(17.0)$ \\
\hline
\end{tabular}

Hayashi K, Horiuchi T, Kusuda S. et al, Mortality rates for extremely low birth weight infants born in Japan in 2005. Pediatrics 2009 123(2): 442-450

Table 2: Numbers of Births and Mortality Rates According to Gestational Age born in 2005 .

\begin{tabular}{|c|c|c|}
\hline Gestational Age & $\begin{array}{c}\text { No. of Survival } \\
\text { No. of Admission }\end{array}$ & Survival Rate \\
\hline 2 wweeks & $0 / 4[0 / 0]$ & $0 \%[0 / 0]$ \\
\hline 21 weeks & $0 / 8[0 / 0]$ & $0 \%[0 / 0]$ \\
\hline 22 weeks & $44 / 241[51 / 164]$ & $18 \%[31 \%]$ \\
\hline 23 weeks & $242 / 568[234 / 416]$ & $43 \%[56 \%]$ \\
\hline
\end{tabular}

Table 3: Survival rates of infants less than 24 weeks of gestation (born between 1995-2001 at 112 hospitals of Japan neonatologists network) [repeated study born between 2002-2004]

Survival rate

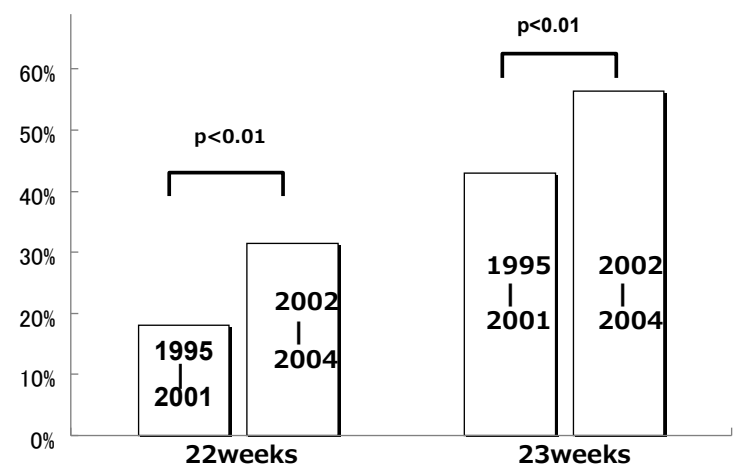

Figure 1: Improvement of survival rate of infants at $22^{\text {nd }}$ week of gestation in two time periods.

after birth and are expected to improve along with the advancement of their postnatal ages. Moreover, it is rather encouraging that majority of survivors are escaped from $\mathrm{CP}$ and from blindness in spite of such extreme prematurity.

\section{Survival rates of ELBW infants at Tokyo Women's Medical University (TWMU)}

TWMU has been reporting relatively high survival rate of ELBW infants in the past and the data was regarded to be the benchmark on caring ELBW infants in Japan [1,3,4,7-9]. The data of TWMU on ELBW infants was also quoted in the textbook of Avery's Neonatology ( $6^{\text {th }}$ edition) as the leading result on infants at 22-23 weeks of gestation [10]. Survival rates of ELBW infants cared at TWMU in 1984 to 2004 are shown in table 5 by gestational age categories. There was no survival at 21 weeks of gestation but were $56 \%$ and $42 \%$ survival at $22^{\text {nd }}$ and $23^{\text {rd }}$ weeks of gestation, respectively. When gestation age goes up to 24 and 25 weeks of gestation, survival rates of such infants were markedly

\begin{tabular}{|c|c|c|c|c|c|c|}
\hline \multirow{2}{*}{$\begin{array}{c}\text { Birth Weight } \\
\text { (grams) }\end{array}$} & $\begin{array}{c}\text { Number of } \\
\text { Admission }\end{array}$ & $\begin{array}{c}\text { Number of } \\
\text { Survive (\%) }\end{array}$ & \multicolumn{4}{|c|}{ Neurological Squeal (\%) } \\
\cline { 4 - 8 } & CP/MR & MR only & Blind & Total \\
\hline $\mathbf{3 0 0}$ & 10 & $1(10 \%)$ & 1 & 0 & 0 & $1(100 \%)$ \\
\hline $\mathbf{3 0 0 - 3 9 9}$ & 87 & $15(17 \%)$ & 2 & 5 & 1 & $7(47 \%)$ \\
\hline $\mathbf{4 0 0 - 4 9 9}$ & 278 & $131(47 \%)$ & 19 & 32 & 6 & $51(39 \%)$ \\
\hline $\mathbf{5 0 0 - 5 9 9}$ & 256 & $132(47 \%)$ & 26 & 33 & 14 & $59(45 \%)$ \\
\hline $\mathbf{6 0 0 - 6 9 9}$ & 189 & $89(47 \%)$ & 13 & 27 & 9 & $41(46 \%)$ \\
\hline $\mathbf{7 0 0 <}$ & 22 & $18(82 \%)$ & 6 & 4 & 0 & $10(56 \%)$ \\
\hline TOTAL & $\mathbf{8 4 2}$ & $\mathbf{3 8 6}$ & $\mathbf{6 7}$ & $\mathbf{1 0 1}$ & $\mathbf{3 0}$ & $\mathbf{1 6 9}$ \\
& & $\mathbf{( 4 6 \% )}$ & $\mathbf{( 1 7 \% )}$ & $\mathbf{( 2 6 \% )}$ & $\mathbf{( 8 \% )}$ & $\mathbf{( 4 4 \% )}$ \\
\hline
\end{tabular}

Table 4: Survival and neurological squeal rates of infants less than 24 weeks of gestation (born in 1995-2001, followed up to 5 years old).

\begin{tabular}{|c|c|}
\hline Gestational Age (Weeks) & No. of survival/No. of admission (survival rate, \%) \\
\hline $\mathbf{2 1}$ & $0 / 1(0.0)$ \\
\hline $\mathbf{2 2}$ & $5 / 9(56)$ \\
\hline $\mathbf{2 3}$ & $11 / 26(42)$ \\
\hline $\mathbf{2 4}$ & $27 / 35(77)$ \\
\hline $\mathbf{2 5}$ & $45 / 49(92)$ \\
\hline $\mathbf{2 6}$ & $44 / 54(82)$ \\
\hline $\mathbf{2 7}$ & $48 / 52(92)$ \\
\hline $\mathbf{2 8}$ & $35 / 39(90)$ \\
\hline $\mathbf{2 9}$ & $21 / 23(91)$ \\
\hline $\mathbf{3 0}$ & $19 / 23(83)$ \\
\hline TOTAL & $14 / 19(74)$ \\
\hline
\end{tabular}

Table 5: Survival Rate of ELBW infants Tokyo Women's Medical University (1984 2004)

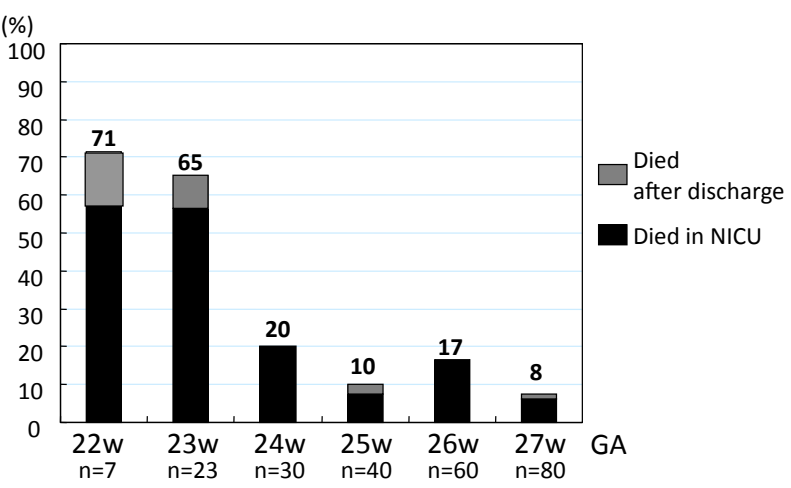

Figure 2: Mortality rate by gestational age (October 1984 to September 2002 in Tokyo Women's Medical University) $(n=240)$.

improved to $77 \%$ and $92 \%$ respectively. It is clear that there is the apparent difference between $23^{\text {rd }}$ and $24^{\text {th }}$ weeks of gestation in regards to the survival rate, which is the important data on the discussion of the viability limit [1] (Figure 2).

\section{Discussion}

Since the survival of infants less than 22 weeks of gestation is negligible, it will be appropriate to recommend no active intervention on such infants unless there is strong parental wish because of the only and the last chance for the mother to have an offspring. On the other hand, if gestational age goes up to 24 weeks, survival rate increases close to $80 \%$. Therefore, it is also appropriate to recommend active intervention unless there are apparent medical conditions to relate with lethal outcome or with severe neurological sequel. How we deal with so-called marginal viable infants of 22 and 23 weeks of gestations are 
Citation: Nishida H (2013) Improved Outcome of Infants Born at less than 24 Weeks of Gestation in Japan. J Health Med Informat S11: 001. doi:10.4172/2157-7420.S11-001

\begin{tabular}{|l|l|}
\hline Stages & Reasons for Death Occurence \\
\hline Intrapertum & Birth asphyxia No active resuscitation due to parent's will \\
\hline Early Neonatal & $\begin{array}{l}\text { Respiratory instability due to immaturity Cardiovascular failure } \\
\text { due to acute adrenal insufficiency and myocardial } \\
\text { immaturity Intraventricular hemorrhage }\end{array}$ \\
\hline Late Neonatal & $\begin{array}{l}\text { Sepsis (especially Candida \& nosocomial, opportunistic } \\
\text { infection) Necrotizing enterocolitise }\end{array}$ \\
\hline Post-Neonatal & $\begin{array}{l}\text { Chronic lung disease, Sudden infant death syndrome, } \\
\text { Abused child }\end{array}$ \\
\hline
\end{tabular}

Table 6: Causes of death of infants at 22-23 weeks of gestation.

\begin{tabular}{|l|l|}
\hline Stages & Site of Infection \\
\hline Prenatal & $\begin{array}{l}\text { Antenatal steroid, tocolitic agents } \\
\text { (intensive discussion with obstetrician and neonatologist) }\end{array}$ \\
\hline At delivery & $\begin{array}{l}\text { Non-traumatic, minimal handling (CS is exceptional) } \\
\text { Deliver with intact fetal membrane and umbilical cord }\end{array}$ \\
\hline After birth & $\begin{array}{l}\text { Promote placental-fetal transfusion (cord milking) } \\
\text { - Prevention infection (prophylactic anti-fungus drugs) }\end{array}$ \\
& $\begin{array}{l}\text { Steroid to stabilize blood pressure } \\
\text { - Bio-protection by Colostrums, Priming intestine }\end{array}$ \\
\hline Ethical consideration & $\begin{array}{l}\text { Viability limit, Do-not-resuscitate order Escape from } \\
\text { eugenic thought }\end{array}$ \\
\hline
\end{tabular}

Table 7: Specific management of infants at 22-23 weeks of gestation.

currently on debate. Though their current survival rates are close to $50 \%$, morbidity is still high and two third of survivors have some degree of neurological handicap. Therefore, medial decision on treating such infants at $22^{\text {nd }}$ and $23^{\text {rd }}$ weeks of gestation should be based on the data of each institute. Our policy of TWMU is to initiate treatments on infants at $22^{\text {nd }}$ and $23^{\text {rd }}$ weeks unless apparent objection is expressed form parents. Therefore, it is essential to discuss with parents before initiating active intervention, desirably before birth of the infant. Frequent causes of death of infants at 22-23 weeks are shown in table 6 . One of the most frequent causes of their death occurs at the time of birth due to asphyxia and due to no-resuscitation following parents' will. For better medical management of these issues, antenatal and perinatal consultations to parents are mandatory. Main medical reasons of neonatal death after birth are related with their extreme prematurity, not only of cardiorespiratory systems but also of skin fragility and immature immunity. Meticulous care to protect fragile skin and to prevent infection is as important as cardio-respiratory assist on managing these extreme premature infants [9]. Specific managements to improve outcome of infants at 22-23 weeks of gestation are suggested as shown in table 7 , though some items quoted on the table are still in debate. Before birth, exchange information and discussion with obstetricians and neonatologists are essential, including use of antenatal steroids, timing of delivery and parents' will for active intervention. Though caesarian section at such early gestations are exceptional, it is desirable to deliver an infant and placenta with connecting umbilical cord as a set covered by intact fetal membrane for the better cardiovascular stabilization during and after delivery process [11]. Before cutting umbilical cord, promoting placental-fetal transfusion by cautious cord milking is helpful to maintain adequate blood volume of the infant [12]. Often postnatal steroid administration is essential to stabilize blood pressure to encounter adrenal cortical insufficiency due to extreme prematurity and stress [13]. Use of umbilical venous catheter as an infusion route for the first 5 to 7 days is inevitable to avoid excess handling to keep peripheral lines [9]. Early enteral instillation of breast milk, especially Colostrums is useful as bio-protection and gut stimulation [9]. Preventing infection by meticulous care and gentle handling to avoid excess stress are also very important. Serial C-reactive protein (CRP) measurements is useful to early detection of infection and moreover, to reduce unnecessary use of antibiotics [14]. Lastly the optimistic attitude toward successful survival by avoiding eugenic though is the most important of all for the success of managing these marginal viable infants [9].

\section{Conclusion}

Current Japanese data on ELBW infants, especially infants less than 24 weeks of gestations are reviewed. Since survival of infants at $21^{\text {s }}$ week of gestation is exceptional and of infants at $24^{\text {th }}$ week of gestation are close to $80 \%$, it is apparent that infants at $22^{\text {nd }}$ and $23^{\text {rd }}$ weeks of gestation are marginal viable and are on the debate of medical and ethical discussion for the feasibility of active intervention at NICU in Japan. Though there are still limited medical knowledge and technology in the care of infants at $22^{\text {nd }}$ and $23^{\text {rd }}$ weeks of gestation, survival rates of such infants born in 2002-2004 have shown significant improvement from those born in 1990-2001. Therefore, we should continue our efforts for the intact survival of these extreme premature infants, while knowing the viability limit based on up-to-date statistics of infants at $22^{\text {nd }}$ and $23^{\text {rd }}$ weeks of gestation.

\section{Acknowledgments}

We appreciate Japan Neonatologist Association for their supportive work.

\section{References}

1. Nishida H, Sakuma I (2007) Limit of viability in Japan: ethical consideration. $J$ Perinatal Med 37: 457-460.

2. Nishida H, Ishizuka Y (1992) Survival rate of extremely low birth weight infants and its effect on the amendment of the eugenic protection act in Japan. Acta Paediatr Jpn 34: 612-616.

3. Oishi M, Nishida H, Sasaki T (1997) Japanese experience with micropremies weighing less than 600 grams born between 1984 to 1993. Pediatrics 99: e7.

4. Nishida H (1993) Outcome of infants born preterm, with special emphasis on extremely low birth weight infants. Baillieres Clin Obstet Gynecol 7: 611-631.

5. Ikeda K, Hayashida S, Hokuto I, Kusuda S, Nishida H (2006) Recent short-term outcomes of ultrapreterm and extremely low birth weight infants in Japan. Neo Reviews 7: e511-e516.

6. Itabashi K, Horiuchi T, Kusuda S, Kabe K, Itani Y, et al. (2005) Mortality Rates for Extremely Low Birth Weight Infants Born in Japan in 2005. Pediatrics 123 445-450.

7. Nishida $\mathrm{H}$ (2002) Marginally viable, fetal infants-who are too young or small to live: Japanese experience. Hot Topics 2002 in Neonatology, 2002, Washington, DC.

8. Nishida $H$ (2004) The importance of nurturing warm heartedness to the young infants, the lesson from neonatal medicine and recent brain research. Presented at the meeting of Vermont-Oxford Neonatal Network, December 11, 2004, Washington DC.

9. Nishida H, Kusuda S (2006) Clinical Guideline on Caring Extremely Low Birth Weight Infants. (3rdedn), Tokyo Medical View Co. Ltd. 2006 (in Japanese)

10. Papageorgiou A, Pleausa E, Kovacs L (2005) The extremely low birth weight infants. In: MacDonald MG, Seshia MMK, Mullett MD, (eds.), Avery's Neonatology: Pathophysiology and Management of the Newborn. (6thedn) Lippincott Williams \& Wilkins, Philadelphia 481.

11. (2001) Personal Communications. IEEE Xplore.

12. Hosono S, Mugishima H, Fujita H, Hosono A, Minato M, et al. (2008) Umbilical cord milking reduces the need for red cell transfusions and improves neonatal adaptation in infants born at less than 29 weeks' gestation: a randomised controlled trial. Archives disease childhood, fetal and neonatal 93: 14-19.

13. Masumoto1 K, Kusuda S, Aoyagi H, Tamura Y, Obonai T, et al. (2008) Comparison of Serum Cortisol Concentrations in Preterm Infants with or without Late-Onset, Circulatory Collapse due to Adrenal Insufficiency of Prematurity. Pediatr Res 63: 686-690.

14. Kawamura M, Nishida H (1995) The usefulness of serial C-reactive protein measurement in managing neonatal infection. Acta Paediatr 84: 10-13. 